\title{
PRODUTIVIDADE E COMPONENTES DA PRODUÇÃO DO AMENDOIM DA SECA EM RAZÃO DA ÉPOCA DE SEMEADURA E DA APLICAÇÃO DE CÁLCIO'
}

\author{
CARLOS ALEXANDRE COSTA CRUSCIOL², EDSON LAZARINI ${ }^{3}$, ALBERTO RICARDO GOLFETO ${ }^{3}$ \\ e MARCO EUSTÁQUIO DE SÁ3
}

\begin{abstract}
RESUMO - Este trabalho teve por objetivo estudar o efeito do calcário, como fornecedor de cálcio, em diferentes épocas de semeadura, na cultura do amendoim cultivar Tatu, sobre os componentes da produção e a produtividade de vagens em semeadura na época considerada seca. O experimento foi conduzido em um Latossolo Vermelho-Escuro, argiloso, em Selvíria, MS. Foram estudadas quatro épocas de semeadura do amendoim da seca (21/1, 4/2, 18/2 e 4/3), combinadas com quatro doses de Ca $\left(0,45,90\right.$ e $\left.135 \mathrm{~kg} \mathrm{ha}^{-1} \mathrm{de} \mathrm{Ca}\right)$, aplicadas no sulco de semeadura, usando como fonte calcário dolomítico com PRNT de $90,1 \%$ e com teores de $21 \%$ de $\mathrm{CaO}$ e $18 \%$ de $\mathrm{MgO}$. Foram avaliados o número de vagens por planta, o número de grãos por vagem e por planta, o peso de 100 grãos, o rendimento e a produtividade das vagens. Conclui-se que: 1) à medida que se atrasa a semeadura, há a probabilidade de ocorrer deficiência hídrica nos períodos vegetativo e reprodutivo, reduzindo a produtividade do amendoim da seca; 2) há boa produtividade de vagens quando a semeadura é realizada até o início do mês de fevereiro; 3) a resposta do amendoim da seca ao Ca é baixa em solos onde inicialmente se tem alto teor de Ca e saturação por bases considerada média, principalmente, quando a disponibilidade hídrica também é um fator limitante; 4) a aplicação de calcário no sulco de semeadura como meio de fornecimento de Ca para a cultura do amendoim é uma prática viável.
\end{abstract}

Termos para indexação: calagem, rendimento de colheitas, vagens, peso.

\section{PRODUCTIVENESS AND YIELD COMPONENTS IN DRY SEASON PEANUT AS AFFECTED BY PLANTING TIME AND CALCIUM FERTILIZATION}

\begin{abstract}
The effect of Ca fertilization and sowing time on yield components and peanut pod yield in the dry season was studied. The experiment was conducted under field conditions in a DarkRed Latosol, loamy texture, in Selvíria, MS, Brazil. Four sowing times (Jan. 21, Feb. 4, Feb. 18, and Mar. 4) were combined with four calcium levels (0, 45, 90 and $135 \mathrm{~kg} \mathrm{ha}^{-1}$ of Ca), applied at the sowing time, into the furrows, utilizing dolomite limestone with PRNT 90.1\% (21\% of CaO and $18 \%$ of $\mathrm{MgO}$ ). The number of pods per plant, number of grains per pod and per plant, 100 grains weight, hulled grains yield and peanut pod yield were determined. It is concluded that: 1) as the sowing is delayed, a water stress may occur in the growing period, and in the reproductive period, reducing the dry-season peanut crop productiveness; 2) there are good yields if planting is accomplished at the beginning of February; 3) the response for $\mathrm{Ca}$ fertilization is low in soils with high $\mathrm{Ca}$ level and medium basis saturation, specially when water conditions are also a limiting factor during dry season crop; 4) lime applied at the sowing time into the furrows is recommended.
\end{abstract}

Index terms: liming, crop yield, pods, weight.

${ }^{1}$ Aceito para publicação em 16 de dezembro de 1999.

${ }^{2}$ Eng. Agrôn., Dr., Dep. de Agricultura e Melhoramento Vegetal, Faculdade de Ciências Agronômicas, UNESP, Caixa Postal 237, CEP 18603-970 Botucatu, SP.

E-mail: crusciol@ fca.unesp.br

${ }^{3}$ Eng. Agrôn., Dr., Dep. de Fitotecnia, Faculdade de Engenharia, UNESP, Caixa Postal 31, CEP 15385-000 Ilha Solteira, SP.

E-mail: lazarini@agr.feis.unespe.br, mesa@agr.feis.unesp.br

\section{INTRODUÇÃO}

O cultivo de amendoim no Brasil ocupa aproximadamente 88.540 ha. No Estado de São Paulo, concentra-se $82 \%$ da produção nacional de grãos (Amendoim, 1998) e 100\% da produção de sementes (Araújo, 1991). Nesse estado, o amendoim é cultivado em duas épocas do ano: a safra das águas, com produti- 
vidade de $2.047 \mathrm{~kg} \mathrm{ha}^{-1}$, e da seca, com $1.537 \mathrm{~kg} \mathrm{ha}^{-1}$; a safra das águas ocupa $77 \%$ do total da área cultivada (Previsões ..., 1992). O último dado de cultivo de amendoim no Estado do Mato Grosso do Sul é de 1994, ano em que foi cultivada uma área de 200 ha com produtividade de $1.500 \mathrm{~kg} \mathrm{ha}^{-1}$ (Amendoim, 1998).

A calagem é uma das práticas recomendadas na condução da cultura, principalmente em solos com baixa saturação por bases, embora seus efeitos sobre a produtividade de grãos e qualidade nem sempre sejam significativos (Fernandez, 1996). No entanto, para alguns autores a fonte para aumentar o nível da Ca no solo depende do pH. Blamey \& Chapman (1982) observaram que a aplicação de calcário, como fornecedor de $\mathrm{Ca}$, aumenta a produção em solo com baixo $\mathrm{pH}(4,5)$, porque reduz o $\mathrm{Al}$ trocável, diminuindo sua toxicidade e melhorando a nutrição nitrogenada, ao passo que o gesso não afeta esses parâmetros. Entretanto, Quaggio et al. (1982) consideram que a aplicação tanto de gesso como de calcário, utilizada corretivamente, aumenta a produção em solo com pH 5,0, já que ambos aumentam a concentração de Ca na zona de frutificação.

Sob deficiência de $\mathrm{Ca}$, as plantas florescem profusamente (Harris \& Brolmann, 1966), mas altas porcentagens dessas flores são inférteis; a fertilidade é incrementada com o aumento do nível de Ca no solo (Wolt \& Adams, 1979). Quando a quantidade de Ca no solo é insuficiente para cobrir os requerimentos do pericarpo e da semente, ocorre aborto de óvulos (Burkhart \& Collins, 1941), produzindo frutos com uma ou nenhuma semente (Colwell \& Brady, 1945b) e, ou, vagens chochas (Cox \& Reid, 1964).

A aplicação de calcário aumenta o número de ramificações secundárias e totais por planta (Fernandez, 1996), e aumenta o número de ginóforos (Reed \& Brady, 1948; Fernandez, 1996), e estes correlacionamse com a produção de sementes (Nakagawa \& Rosolem, 1982).

A produção de sementes correlaciona-se com o número de vagens por planta (Nakagawa \& Rosolem, 1982); no entanto, o efeito do calcário sobre esse parâmetro não está bem caracterizado; pode haver tendência de incremento (Rossetto, 1993), e quando há um aumento, é devido, em parte, ao aumento das ramificações (Fernandez, 1996).

O número de sementes por vagem é uma característica de alta herdabilidade, mas pode haver aborto de sementes (Smith, 1956). Isso pode acontecer por deficiência de Ca. Nessa situação, ocorre uma diminuição do número de cavidades cheias nos frutos com duas sementes (Colwell \& Brady, 1945b). Entretanto, com Ca disponível e sob déficit hídrico nos frutos com uma e duas sementes, diminui a porcentagem destas (Skelton \& Shear, 1971). Nakagawa et al. (1993) e Fernandez (1996) observaram aumento do número de sementes por vagem quando aplicaram calcário em solo com pH 5,6 e 4,2, teor de Ca igual a 4,0 e 5,5 $\mathrm{mmol}_{\mathrm{c}} \mathrm{dm}^{-3}$, e saturação por bases (V\%) de 22 e 19,5, respectivamente. No entanto, Fornasieri et al. (1987), Caires (1990), Rossetto (1993) e Rossetto et al. (1998) não encontraram efeito significativo da calagem nesse parâmetro. $\mathrm{O}$ número de sementes por vagem é determinado no momento da fertilização. Desta forma, a disponibilidade de Ca é de real importância, já que este nutriente intervém no crescimento e direção do tubo polínico (Mascarenhas \& Machkis, 1964).

Os efeitos da calagem na produção de vagens são contraditórios. As respostas estão, em vários trabalhos, relacionadas ao teor de $\mathrm{Ca}$ no solo e ao nível de saturação por bases do solo (Quaggio et al., 1982; Caires, 1990; Fernandez, 1996). Segundo Cox et al. (1982), as plantas de amendoim apresentam relativa tolerância à acidez do solo, por isso, as respostas à calagem não são detectadas em muitos casos. Outra explicação é a baixa disponibilidade hídrica no solo, principalmente por ocasião da máxima necessidade da planta (Rossetto, 1993; Rossetto et al., 1998), o que reduz a absorção do nutriente do solo (Kvien et al., 1988; Alva et al., 1991).

Em solos com valores de $\mathrm{pH}(4,2$ a 5,6$)$ e saturação por bases (12 a 41,6\%) considerados de muito baixos a baixos (Raij et al., 1996), foi observado, por alguns pesquisadores, aumento da produtividade (Fornasieri et al., 1987; Smyth \& Cravo, 1992; Nakagawa et al., 1993; Fernandez, 1996), enquanto 
outros não observaram o mesmo efeito (Nakagawa et al., 1993; Rossetto, 1993).

Este trabalho teve por objetivo estudar o efeito do calcário como fornecedor de cálcio, em diferentes épocas de semeadura, na cultura do amendoim da seca, sobre os componentes da produção e a produtividade de vagens.

\section{MATERIAL E MÉTODOS}

O experimento foi conduzido na Fazenda de Ensino e Pesquisa (FEP) pertencente à Faculdade de Engenharia câmpus de Ilha Solteira - UNESP, localizada no município de Selvíria, MS, apresentando como coordenadas geográficas $51^{\circ} 22^{\prime} \mathrm{W}$ e $20^{\circ} 22^{\prime} \mathrm{S}$, com Latossolo Vermelho- Escuro, argiloso, classificado por Demattê (1980), que anteriormente foi cultivado com milho na safra de verão (safra das águas), do ano 1991. Essa região não tem tradição no cultivo do amendoim. Na Tabela 1 estão contidos os resultados da análise química do solo amostrado na área experimental, na camada de $0-0,20 \mathrm{~m}$.

Os dados diários referentes às precipitações pluviais e às temperaturas máxima e mínima diárias, do período de condução do experimento, coletados no posto meteorológico da FEP, encontram-se na Fig. 1, e os dados de precipitação durante o ciclo e nos períodos da emergência ao florescimento e do florescimento à colheita, na Tabela 2 .

Foram estudadas quatro épocas de semeadura do amendoim da seca, cultivar Tatu 53, ( $E_{1}-21 / 1, E_{2}-4 / 2$, $E_{3}-18 / 2$ e $\left.E_{4}-4 / 3\right)$; a emergência das plântulas ocorreu em $30 / 1\left(E_{1}\right), 10 / 2\left(E_{2}\right), 26 / 2\left(E_{3}\right)$ e $11 / 3\left(E_{4}\right)$, respectivamente. Essas épocas de semeadura foram combinadas com quatro doses de $\mathrm{Ca}\left(\mathrm{Ca}_{1}=0 \mathrm{~kg} \mathrm{ha}^{-1} \mathrm{de} \mathrm{Ca}, \mathrm{Ca}_{2}=45 \mathrm{~kg} \mathrm{ha}^{-1}\right.$ de $\mathrm{Ca}, \mathrm{Ca}_{3}=90 \mathrm{~kg} \mathrm{ha}^{-1}$ de $\mathrm{Ca}$ e $\mathrm{Ca}_{4}=135 \mathrm{~kg} \mathrm{ha}^{-1} \mathrm{de} \mathrm{Ca}$ ), aplicadas no sulco de semeadura, objetivando realizar, em uma única operação, a adubação de semeadura e o fornecimento de Ca via calcário (técnica empregada por alguns agricultores, da região oeste do Estado de São Paulo). Utilizou-se, como fonte de $\mathrm{Ca}$, calcário dolomítico com PRNT de $90,1 \%$ e com teores de $21 \%$ de $\mathrm{CaO}$ e $18 \%$ de $\mathrm{MgO}$. Vale ressaltar que não foi realizada calagem convencional, nem anteriormente ao cultivo do milho nem por ocasião da instalação deste trabalho.
O delineamento experimental empregado foi o de blocos ao acaso, com quatro repetições, em esquema de parcelas subdivididas, sendo as parcelas constituídas pelas épocas de semeadura e as subparcelas pelas doses de Ca. Foram deixados 6 m entre as parcelas (épocas) para o trânsito de máquinas. As subparcelas (doses de $\mathrm{Ca}$ ) constaram de seis fileiras de $5 \mathrm{~m}$ de comprimento espaçadas de $0,5 \mathrm{~m}$. Foi considerada como área útil para as avaliações as quatro fileiras centrais de cada subparcela, desprezando-se $0,5 \mathrm{~m}$ em ambas extremidades de cada fileira de plantas, que resultou em $8 \mathrm{~m}^{2}$.

O solo foi preparado com uma aração e duas gradagens, a saber: a primeira, levada a efeito logo após a aração, e a segunda, às vésperas da semeadura. A adubação constou da aplicação nos sulcos de semeadura, de $10 \mathrm{~kg} \mathrm{ha}^{-1}$ de N, $75 \mathrm{~kg} \mathrm{ha}^{-1}$ de $\mathrm{P}_{2} \mathrm{O}_{5}$ e $25 \mathrm{~kg} \mathrm{ha}^{-1}$ de $\mathrm{K}_{2} \mathrm{O}$, pela fórmula química comercial 4-30-10.

Utilizou-se uma densidade de 18 sementes viáveis por metro linear. As sementes, antes da semeadura, foram tratadas com fungicida dissulfeto de tetrametil-tiuram, na forma de pó seco, na dose de $175 \mathrm{~g}$ de i.a. por $100 \mathrm{~kg}$ de sementes, para proteção das plântulas contra fungos de solo.

Para o bom estabelecimento das parcelas, fizeram-se, quando necessário, irrigações para uma germinação e emergência uniformes das plântulas, sendo cessada posteriormente, ficando todos os tratamentos dependentes da precipitação pluvial natural. Assim, as irrigações foram realizadas com um sistema de aspersão autopropelido e foi aplicada uma lâmina de $15 \mathrm{~mm}$ por irrigação nas seguintes datas: 22/1 e 24/1 ( $\left.E_{1}\right)$ e, 20/2 e 23/2 ( $\left.E_{3}\right)$. Dez dias após a emergência das plântulas de cada subparcela, em todas as épocas, foi realizado um desbaste, deixando uma densidade de 14 plantas por metro.

O controle de plantas daninhas foi realizado com a aplicação do herbicida pré-emergência alachlor, após a semeadura das parcelas de cada época, na dosagem de 2,64 $\mathrm{kg} \mathrm{ha}^{-1}$ de i.a., e por uma capina manual durante o desenvolvimento da cultura em que foi realizado o chegamento de terra junto às plantas (amontoa), assim que surgiram as primeiras flores.

Quando necessário, realizou-se a aplicação do inseticida methamidophós na dosagem de $0,33 \mathrm{~L} \mathrm{ha}^{-1}$ de i.a, para o controle de trips (Enneothrips flavens e Caliothrips

TABELA 1. Análise química do solo (0-20 cm). Fazenda de Ensino e Pesquisa, Selvíria, MS, 1991.

\begin{tabular}{|c|c|c|c|c|c|c|c|c|c|}
\hline $\begin{array}{c}\text { M.O. } \\
\left(\mathrm{g} \mathrm{dm}^{-3}\right)\end{array}$ & $\begin{array}{c}\mathrm{pH} \\
\left(\mathrm{CaCl}_{2}\right)\end{array}$ & $\begin{array}{c}\text { P resina } \\
\left(\mathrm{mg} \mathrm{dm}^{-3}\right)\end{array}$ & $\mathrm{H}+\mathrm{Al}$ & K & $\begin{array}{l}\mathrm{Ca} \\
--(\mathrm{m}\end{array}$ & $\begin{array}{l}\mathrm{Mg} \\
\left.\mathrm{dm}^{3}\right)\end{array}$ & SB & CTC & $\begin{array}{l}\mathrm{V} \\
(\%)\end{array}$ \\
\hline 36 & 4,6 & 10 & 47 & 2,4 & 26 & 18 & 46,4 & 93,4 & 50 \\
\hline
\end{tabular}




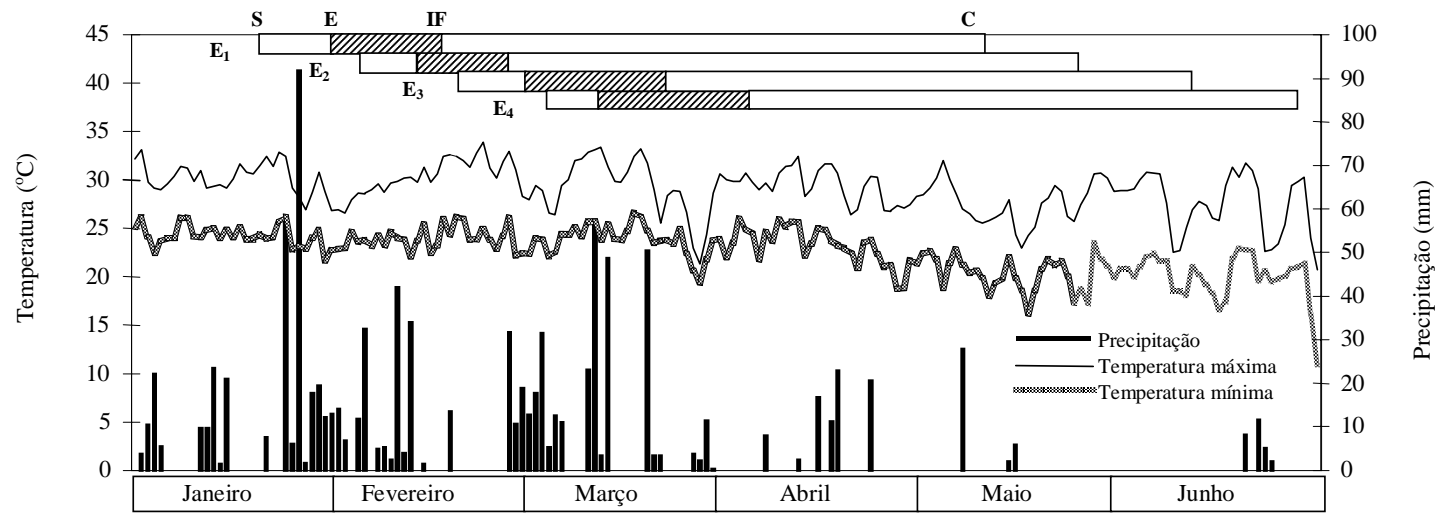

FIG. 1. Dados diários de precipitação pluvial $(\mathrm{mm})$, temperatura máxima e mínima $\left({ }^{\circ} \mathrm{C}\right)$, durante a condução do experimento. Fazenda de Ensino e Pesquisa - Faculdade de Engenharia, câmpus de Ilha Solteira/UNESP, Selvíria, MS, 1991. $\left(E_{1}=\right.$ semeadura 21/1; $E_{2}=$ semeadura $4 / 2 ; E_{3}=$ semeadura $18 / 2 ; E_{4}=$ semeadura $4 / 3 ; S=$ semeadura; $E$ = emergência; IF = início do florescimento; $\mathrm{C}=$ colheita).

TABELA 2. Precipitação pluvial $(\mathrm{mm})$ e, entre parênteses, precipitação pluvial média diária $\left(\mathrm{mm}^{\mathrm{d}} \mathbf{d i a}^{-1}\right)$, durante os períodos da emergência ao início do florescimento, do início do florescimento à colheita e durante o ciclo da cultura, em razão das épocas de semeadura (E) do amendoim da seca. Selvíria, MS, 1991.

\begin{tabular}{lcccc}
\hline \multirow{2}{*}{ Período } & \multicolumn{4}{c}{ Épocas de semeadura } \\
\cline { 2 - 4 } & $\mathrm{E}_{1}(21 / 1)$ & $\mathrm{E}_{2}(4 / 2)$ & $\mathrm{E}_{3}(18 / 2)$ & $\mathrm{E}_{4}(4 / 3)$ \\
\hline Emergência-florescimento & $186,2(8,9)$ & $176,3(8,0)$ & $339,1(14,7)$ & $184,9(7,7)$ \\
Florescimento-colheita & $462,4(5,9)$ & $353,1(4,6)$ & $139,3(1,7)$ & $142,9(1,7)$ \\
Ciclo da cultura & $648,6(6,6)$ & $529,4(5,3)$ & $478,4(4,6)$ & $327,8(3,1)$ \\
\hline
\end{tabular}

brasiliensis), e a aplicação de benomyl na dosagem de $125 \mathrm{~g} \mathrm{ha}^{-1}$ de i.a., para o controle de cercosporioses (mancha-preta - Cercosporidium personatum -, e mancha-castanha-Cercospora arachidicola).

Durante a condução do experimento, foram avaliados os parâmetros fenológicos: florescimento - definido pelo número de dias transcorridos da emergência das plântulas até o surgimento da primeira flor, e ciclo da cultura - definido pelo número de dias transcorridos da emergência das plântulas até quando $70 \%$ dos frutos apresentavam-se com o interior escuro e as sementes com tegumento de coloração vermelha. Esses parâmetros não foram submetidos a análise estatística, porque foram determinados quando a maioria das repetições de cada época apresentava tais estágios.

A colheita foi efetuada manualmente e individualmente por subparcela, utilizando a mesma técnica empregada para definir o ciclo da cultura. A seguir, após a secagem à som- bra, foi realizada a trilha manual e a limpeza do material, separando as impurezas (torrões, folhas e ramos) das vagens. Em laboratório, determinaram-se o peso das vagens colhidas e o teor de água pelo método da estufa (Brasil, 1992), e calculou-se a produtividade por hectare $\left(\mathrm{kg} \mathrm{ha}^{-1}\right)$ a 13\% (base úmida). Das vagens colhidas, também, verificaram-se o rendimento, pela relação peso de grão/peso de vagens, e o peso de 100 grãos.

Durante a colheita de cada subparcela, foram coletadas 10 plantas, aleatoriamente dentro da fileira, nas quais, após despencadas, determinaram-se o número de vagens (granadas, chochas e podres) por planta, e número de grãos por vagem e por planta.

Os dados obtidos foram analisados estatisticamente, sem transformação, segundo o delineamento em blocos ao acaso, com quatro repetições. Nas comparações das médias dos tratamentos, adotou-se o teste de Tukey a $5 \%$ de probabilidade. 


\section{RESULTADOS E DISCUSSÃO}

Os resultados do número de dias para o início do florescimento, e do ciclo cultural nas diferentes épocas de semeadura estão contidos na Tabela 3, onde pode-se verificar que semeaduras mais tardias, no cultivo da seca reflete um aumento no número de dias para início do florescimento da cultura do amendoim. Dessa forma, a época 1 apresentou 21 dias, e a época 4, 24 dias para início do florescimento. A mesma constatação pode ser aplicada ao ciclo da cultura, que aumentou nas semeaduras mais tardias, passando de 99 dias na época 1 (final de janeiro) para 107 dias na época 4 (início de março), causado, provavelmente, pela diminuição da temperatura da época 1 até a época 4, como foi constatado pelos dados contidos na Fig. 1. Nakagawa et al. (1986) também observaram maior ciclo da cultura do amendoim cultivado na seca em relação ao ciclo das águas.

Semeaduras realizadas em fins de janeiro até fevereiro/março, que caracterizam o cultivo da seca, resultam em culturas com ciclos maiores, pela maturação mais lenta, pois nessa época as temperaturas são mais baixas em relação às do cultivo das águas (San Martin, 1987).

TABELA 3. Número de dias após a emergência (DAE) decorridos até o início do florescimento e ciclo da cultura, em relação à da época de semeadura (E) do amendoim da seca. Selvíria, MS, 1991.

\begin{tabular}{lcccc}
\hline Período & \multicolumn{4}{c}{ Época de semeadura } \\
\cline { 2 - 5 } & $\mathrm{E}_{1}(21 / 1)$ & $\mathrm{E}_{2}(4 / 2)$ & $\mathrm{E}_{3}(18 / 2)$ & $\mathrm{E}_{4}(4 / 3)$ \\
\hline Emergência-florescimento & 21 & 22 & 23 & 24 \\
Ciclo da cultura & 99 & 99 & 103 & 107 \\
\hline
\end{tabular}

O crescimento vegetativo da planta está diretamente relacionado com a temperatura, de tal forma que a velocidade de surgimento das folhas na haste principal aumenta com a temperatura, sendo maior em torno dos $30^{\circ} \mathrm{C}$ (Ono, 1979; Leong \& Ong, 1983). A temperatura, além de afetar o crescimento vegetativo, influencia o início do florescimento; as temperaturas abaixo de $25-27^{\circ} \mathrm{C}$ ocasionaram um retardamento deste estágio (Ketring, 1979). Os dados contidos na Fig. 1 confirmam a diminuição de temperatura da época 1 até a colheita da época 4, justificando o aumento do ciclo da cultura nas semeaduras mais tardias.

A produtividade de vagens (Tabela 4) não foi modificada pela aplicação de calcário como fornecedor de $\mathrm{Ca}$, e ocorreu influência apenas das épocas de semeadura. A aplicação do calcário no sulco de semeadura certamente elevou o teor de Ca nessa faixa do solo, mas não foi constatado aumento na produtividade de vagens, provavelmente pelo fato de este elemento presente no solo (Tabela 1) estar em um teor considerado alto, embora a saturação por bases tenha sido considerada baixa (Raij et al., 1996). As épocas 3 e 4 apresentaram as menores produtividades de vagens, diferindo significativamente das épocas 1 e 2. De maneira geral, a época 1 foi a mais apropriada para o cultivo de amendoim da seca na região estudada, pois é possível realizar semeaduras até aproximadamente a época 2 (4/2), com obtenção de produtividades ao redor de $1.600 \mathrm{~kg} \mathrm{ha}^{-1}$. A partir desse período, qualquer semeadura sem irrigação torna-se inviável, uma vez que o ciclo da cultura aumenta (Tabela 3), levando a maior probabilidade de ocorrência de veranicos na fase reprodutiva (florescimento e desenvolvimento dos frutos) por causa da diminuição das precipitações pluviais

TABELA 4. Produtividade de vagens em relação à época de semeadura e doses de cálcio na cultura do amendoim da seca. Selvíria, MS, 1991.

\begin{tabular}{|c|c|c|c|c|c|}
\hline \multirow{2}{*}{$\begin{array}{l}\text { Época de } \\
\text { semeadura }\end{array}$} & \multicolumn{4}{|c|}{ Doses de cálcio ${ }^{2}$} & \multirow[t]{2}{*}{ Média } \\
\hline & $\mathrm{Ca}_{1}$ & $\mathrm{Ca}_{2}$ & $\mathrm{Ca}_{3}$ & $\mathrm{Ca}_{4}$ & \\
\hline $\mathrm{E}_{1}(21 / 1)$ & 2.157 & 2.314 & 1.952 & 1.839 & $2.066 \mathrm{a}$ \\
\hline$E_{2}(4 / 2)$ & 1.534 & 1.418 & 1.560 & 1.986 & $1.624 b$ \\
\hline $\mathrm{E}_{3}(18 / 2)$ & 770 & 784 & 748 & 836 & $784 c$ \\
\hline$E_{4}(4 / 3)$ & 405 & 784 & 739 & 683 & $653 c$ \\
\hline Média & $1.217 \mathrm{~A}$ & $1.325 \mathrm{~A}$ & $1.250 \mathrm{~A}$ & $1.336 \mathrm{~A}$ & \\
\hline
\end{tabular}

${ }^{1}$ Médias seguidas de mesma letra não diferem entre si pelo teste de Tukey a 5\% de probabilidade; $\mathrm{CV}=24,7 \%$.

${ }^{2} \mathrm{Ca}_{1}: 0 \mathrm{~kg} \mathrm{ha}{ }^{-1} ; \mathrm{Ca}_{2}: 45 \mathrm{~kg} \mathrm{ha}^{-1} ; \mathrm{Ca}_{3}: 90 \mathrm{~kg} \mathrm{ha}^{-1} ; \mathrm{Ca}_{4}: 135 \mathrm{~kg} \mathrm{ha}^{-1}$. 
(Tabela 2 e Fig. 1). Além disso, a menor disponibilidade hídrica leva a menor disponibilidade de $\mathrm{Ca}$ e absorção pela planta. Para Kvien et al. (1988) e Alva et al. (1991), o teor de Ca nos frutos e nas sementes de amendoim depende principalmente do teor do elemento na solução do solo e da água disponível.

Os resultados referentes à ausência de efeito das doses de Ca sobre a produtividade de vagens são confirmados por Tella et al. (1971), Neptune et al. (1982), Quaggio et al. (1982), Caires $(1990,1994)$ e Rossetto (1993). No entanto, não estão de acordo com os obtidos por Nakagawa et al. (1993), Fernandez (1996) e Fernandez et al. (1997), que verificaram incremento na produtividade de vagens com a aplicação de calcário. Os dados alcançados neste trabalho podem ser atribuídos à relativa tolerância das plantas de amendoim à acidez do solo; por isso, as respostas à calagem, em termos de produção, não são detectadas, em muitos casos (Cox et al., 1982).

Quanto ao número de vagens por planta (Tabela 5), analisando a interação através do desdobramento de épocas dentro de $\mathrm{Ca}$, verifica-se que houve efeito significativo em todas as doses de $\mathrm{Ca}$. $\mathrm{Em} \mathrm{Ca}_{1}$ e $\mathrm{Ca}_{4}$ a época 4 proporcionou menor número de vagens por planta, diferindo significativamente das demais. $\mathrm{Na}$ dose $\mathrm{Ca}_{2}$, ocorreu uma redução do número de vagens por planta da época 1 para a época 4 , na qual a época 1 diferiu significativamente das épocas $3 \mathrm{e}$ 4. Quanto à dose $\mathrm{Ca}_{3}$, houve diferença significativa somente entre as épocas $1 \mathrm{e} 4$. Constata-se que houve uma redução do número de vagens por planta nas semeaduras realizadas mais tarde (épocas 3 e 4 ), devendo-se isso, provavelmente, à redução da disponibilidade de água para a cultura, durante o período de formação de vagens, nessas épocas (Tabela 2 e Fig. 1). No entanto, verifica-se que a dose $\mathrm{Ca}_{3}$ na época 4 proporcionou valores estatisticamente superiores em relação à testemunha, provavelmente pelo efeito de massa, ou seja, pela maior concentração do elemento na zona radicular e de frutificação, uma vez que a aplicação de calcário foi realizada no sulco de semeadura.

TABELA 5. Número de vagens e número de grãos por planta, peso de 100 grãos e rendimento em relação à época de semeadura e doses de cálcio na cultura do amendoim da seca. Selvíria, MS, $1991^{1}$.

\begin{tabular}{|c|c|c|c|c|}
\hline \multirow{2}{*}{$\begin{array}{c}\text { Época de } \\
\text { semeadura }\end{array}$} & \multicolumn{4}{|c|}{ Doses de cálcio ${ }^{2}$} \\
\hline & $\mathrm{Ca}_{1}$ & $\mathrm{Ca}_{2}$ & $\mathrm{Ca}_{3}$ & $\mathrm{Ca}_{4}$ \\
\hline & \multicolumn{4}{|c|}{ Número de vagens por planta } \\
\hline $\mathrm{E}_{1}(21 / 1)$ & $7,8 \mathrm{Aa}$ & $10,8 \mathrm{Aa}$ & $11,2 \mathrm{Aa}$ & $9,2 \mathrm{Aa}$ \\
\hline $\mathrm{E}_{2}(4 / 2)$ & $10,0 \mathrm{Aa}$ & 9,9Aab & $8,1 \mathrm{Aab}$ & $10,4 \mathrm{Aa}$ \\
\hline $\mathrm{E}_{3}(18 / 2)$ & 7,2Aa & $7,3 \mathrm{Abc}$ & $9,4 \mathrm{Aab}$ & 9,8Aa \\
\hline \multirow[t]{2}{*}{$\mathrm{E}_{4}(4 / 3)$} & $2,7 \mathrm{Bb}$ & $4,8 \mathrm{ABc}$ & $3,8 \mathrm{Ab}$ & $3,8 \mathrm{ABb}$ \\
\hline & \multicolumn{4}{|c|}{ Número de grãos por planta } \\
\hline $\mathrm{E}_{1}(21 / 1)$ & $17,8 \mathrm{Ba}$ & $26,4 \mathrm{ABa}$ & $28,5 \mathrm{Aa}$ & $19,0 \mathrm{Ba}$ \\
\hline $\mathrm{E}_{2}(4 / 2)$ & $22,4 \mathrm{Aa}$ & $21,2 \mathrm{Aab}$ & $19,4 \mathrm{Aab}$ & $24,6 \mathrm{Aa}$ \\
\hline $\mathrm{E}_{3}(18 / 2)$ & $16,9 \mathrm{Aa}$ & $16,8 \mathrm{Ab}$ & $20,4 \mathrm{Aab}$ & $18,8 \mathrm{Aab}$ \\
\hline \multirow[t]{2}{*}{$E_{4}(4 / 3)$} & $6,3 \mathrm{Ab}$ & $13,1 \mathrm{Ab}$ & $14,8 \mathrm{Ab}$ & $9,7 \mathrm{Ab}$ \\
\hline & \multicolumn{4}{|c|}{ Peso de 100 grãos (g) } \\
\hline $\mathrm{E}_{1}(21 / 1)$ & $38,1 \mathrm{Aab}$ & $37,9 \mathrm{Aab}$ & $40,9 \mathrm{Aa}$ & $39,0 \mathrm{Aab}$ \\
\hline$E_{2}(4 / 2)$ & $41,6 \mathrm{Aa}$ & $40,3 \mathrm{Aab}$ & $40,0 \mathrm{Aab}$ & $39,0 \mathrm{Aab}$ \\
\hline $\mathrm{E}_{3}(18 / 2)$ & $37,2 \mathrm{Bb}$ & $41,7 \mathrm{Aa}$ & $41,0 \mathrm{ABa}$ & $40,7 \mathrm{ABa}$ \\
\hline \multirow[t]{2}{*}{$E_{4}(4 / 3)$} & $35,9 \mathrm{Ab}$ & $36,5 \mathrm{Ab}$ & $36,3 \mathrm{Ab}$ & $34,7 \mathrm{Ab}$ \\
\hline & \multicolumn{4}{|c|}{ Rendimento $(\%)$} \\
\hline $\mathrm{E}_{1}(21 / 1)$ & $73,2 \mathrm{Aa}$ & $77,0 \mathrm{Aa}$ & $75,5 \mathrm{Aa}$ & $77,5 \mathrm{Aa}$ \\
\hline $\mathrm{E}_{2}(4 / 2)$ & $69,2 \mathrm{Aa}$ & $71,5 \mathrm{Aa}$ & $72,8 \mathrm{Aa}$ & $70,5 \mathrm{Aab}$ \\
\hline $\mathrm{E}_{3}(18 / 2)$ & $70,8 \mathrm{Aa}$ & $74,5 \mathrm{Aa}$ & $72,8 \mathrm{Aa}$ & $70,5 \mathrm{Aab}$ \\
\hline$E_{4}(4 / 3)$ & $65,2 \mathrm{Ba}$ & $76,5 \mathrm{Aa}$ & $68,8 \mathrm{ABa}$ & $65,2 \mathrm{Bb}$ \\
\hline
\end{tabular}

Pesq. agropec. bras., Brasília, v.35, n.8, p.1549-1558, ago. 2000 
A deficiência hídrica reduz a produção de flores, e o efeito é proporcional, diminuindo sensivelmente o número de vagens por planta, uma vez que há redução na produção de fotoassimilados (Rao et al., 1988). Desdobrando a interação doses de Ca dentro de épocas, verifica-se que houve efeito significativo apenas na época 4, na qual a dose $\mathrm{Ca}_{3}$ diferiu estatisticamente da dose de $\mathrm{Ca}_{1}$, e ambas não diferiram das demais $\left(\mathrm{Ca}_{2}\right.$ e $\left.\mathrm{Ca}_{4}\right)$. Caires $(1990,1994)$ e Rossetto (1993) não verificaram efeito da calagem sobre o número de vagens por planta, embora tenha havido tendência de aumento deste, na presença de Ca.

Fornasieri et al. (1987) também não conseguiram aumentar o número de vagens por planta mediante a utilização de calcário como corretivo, mas isso tornou-se possível com o emprego de calcário em cobertura, o que resultou em acréscimos na produtividade de amendoim em vagens. Dessa forma, a aplicação de calcário em cobertura no estágio inicial de florescimento parece ser mais eficiente do que o calcário aplicado como corretivo para o fornecimento de $\mathrm{Ca}$, o qual, de acordo com Colwell \& Brady (1945a) e Walker et al. (1981), previne o abortamento dos óvulos fertilizados, além de proporcionar aumento no número de vagens. Outra opção seria, em uma única operação, aplicação do calcário no sulco junto com a semeadura, eliminando a técnica de fornecimento de Ca via cobertura, uma vez que o calcário tem baixa movimentação no solo, não resultando em prejuízo à nutrição da planta pelo nutriente no período de maior necessidade.

No que se refere ao número de grãos por vagem (Tabela 6), verifica-se que não houve efeito dos tratamentos sobre este parâmetro. Os resultados, quan- to ao efeito do $\mathrm{Ca}$, confirmam os obtidos por Caires (1990, 1994), que também não observou efeito de doses de calcário sobre o número de grãos por vagem, em solos com $36 \%$ e $13 \%$ de saturação por bases (V) e 11,4 e 6,0 $\mathrm{mmol}_{\mathrm{c}} \mathrm{dm}^{-3} \mathrm{de} \mathrm{Ca}$, respectivamente, ou seja, valores bem inferiores aos do solo do presente trabalho. Fornasieri et al. (1987) também não verificaram aumento do número de grãos por vagem pela utilização de calcário como corretivo, mas isso se tornou possível com o emprego de calcário em cobertura, o que se reverteu em acréscimos na produção de amendoim em vagens. No entanto, Nakagawa et al. (1993) observaram aumento do número de grãos por vagens, quando aplicaram calcário num solo com $\mathrm{V}=22 \%$ e $4 \mathrm{mmol}_{\mathrm{c}} \mathrm{dm}^{-3} \mathrm{de} \mathrm{Ca}$. O número de grãos por vagem é determinado no momento da fertilização. Embora seja uma característica de alta herdabilidade, pode ocorrer aborto de óvulos (Smith, 1956) pela deficiência de Ca (Burkhart \& Collins, 1941).

Na Tabela 5 estão contidos os valores do número de grãos por planta, que são valores obtidos da combinação do número de vagens por planta e o número de grãos por vagem. Desdobrando a interação épocas dentro de doses de $\mathrm{Ca}$, verifica-se que houve efeito significativo em todas as doses, nas quais a época 4 foi a que proporcionou os menores valores. Isso, deve-se, provavelmente, a um efeito sinergístico proporcionado pela combinação dos componentes, número de vagens por planta (Tabela 5) e número de grãos por vagem (Tabela 6), já que não houve efeito da aplicação de Ca nas demais épocas $\left(E_{2}, E_{3}\right.$ e $\left.E_{4}\right)$ e utilizou-se a mesma população de plantas em todos os tratamentos. Assim, esses resultados são, em par-

TABELA 6. Número de grãos por vagem em relação à época de semeadura e doses de cálcio na cultura do amendoim da seca. Selvíria, MS, 1991¹.

\begin{tabular}{llllll}
\hline \multirow{2}{*}{$\begin{array}{c}\text { Época de } \\
\text { semeadura }\end{array}$} & \multicolumn{4}{c}{ Doses de cálcio ${ }^{2}$} & Média \\
\cline { 2 - 5 } & $\mathrm{Ca}_{1}$ & $\mathrm{Ca}_{2}$ & $\mathrm{Ca}_{3}$ & $\mathrm{Ca}_{4}$ & $2,3 \mathrm{a}$ \\
\hline $\mathrm{E}_{1}(21 / 1)$ & 2,3 & 2,4 & 2,6 & 2,0 & $2,3 \mathrm{a}$ \\
$\mathrm{E}_{2}(4 / 2)$ & 2,2 & 2,1 & 2,4 & 2,4 & $2,2 \mathrm{a}$ \\
$\mathrm{E}_{3}(18 / 2)$ & 2,4 & 2,4 & 2,2 & 2,0 & $2,4 \mathrm{a}$ \\
$\mathrm{E}_{4}(4 / 3)$ & 2,4 & 2,7 & 2,2 & 2,4 & \\
\hline Média & $2,3 \mathrm{~A}$ & $2,4 \mathrm{~A}$ & $2,3 \mathrm{~A}$ & $2,2 \mathrm{~A}$ & \\
\hline
\end{tabular}

${ }^{1}$ As médias não diferem significativamente entre si pelo teste de Tukey, a 5\% de probabilidade; $\mathrm{CV}=14,3 \%$

${ }^{2} \mathrm{Ca}_{1}: 0 \mathrm{~kg} \mathrm{ha}^{-1} ; \mathrm{Ca}_{2}: 45 \mathrm{~kg} \mathrm{ha}^{-1} ; \mathrm{Ca}_{3}: 90 \mathrm{~kg} \mathrm{ha}^{-1} ; \mathrm{Ca}_{4}: 135 \mathrm{~kg} \mathrm{ha}^{-1}$. 
te, reflexo dos dados obtidos com relação ao número de vagens por planta (Tabela 5), uma vez que não houve efeito dos tratamentos sobre o número de grãos por vagem (Tabela 6). Dessa forma, apenas evidenciam maior efeito de épocas de semeadura sobre esse parâmetro, no qual houve redução do número de grãos por planta à medida que as semeaduras foram realizadas mais tardiamente.

No que se refere ao peso de 100 grãos (Tabela 5), verifica-se que houve efeito da interação épocas e doses de Ca. Desdobrando doses dentro de épocas, os dados permitem constatar efeito significativo apenas na época 3, na qual houve resposta à calagem apenas na dose $\mathrm{Ca}_{2}$ em relação a $\mathrm{Ca}_{1}$, diferindo estatisticamente. Fornasieri et al. (1987) não verificaram aumento no peso de 100 grãos da cultivar Tatu, com a aplicação de calcário corretivamente, à semelhança dos resultados obtidos por Caires (1990, 1994). Segundo York Junior \& Colwell (1951), uma das funções primárias do Ca na nutrição do amendoim é auxiliar no maior desenvolvimento dos grãos, mas os resultados positivos são mais evidentes em solos com baixo teor de Ca. De acordo com Caires (1994), o teor de Ca no solo de $5 \mathrm{mmol}_{\mathrm{c}} \mathrm{dm}^{-3}$, não é tão baixo a ponto de afetar o desenvolvimento dos grãos, o que pode ser uma das explicações para a ausência de resposta a doses de $\mathrm{Ca}$, observada neste trabalho, já que o teor original de Ca trocável estava em torno de $26 \mathrm{mmol}_{\mathrm{c}} \mathrm{dm}^{-3}$, considerado alto por Raij et al. (1996). Entretanto, Fernandez (1996) obteve resposta à calagem num solo com teor de 5,5 $\mathrm{mmol}_{\mathrm{c}} \mathrm{dm}^{-3} \mathrm{de} \mathrm{Ca}$ trocável, confirmando os resultados obtidos por Nakagawa et al. $(1990,1993)$ em solos com teores de Ca trocável de 7,9 e 6,6 $\mathrm{mmol}_{\mathrm{c}} \mathrm{dm}^{-3}$, respectivamente. Essa divergência de resultados pode estar relacionada com a diferença de produtividade obtida nos diversos trabalhos relatados, o que leva a quantidades requeridas de $\mathrm{Ca}$ desiguais. Assim, partindo dessa premissa, a resposta à aplicação de Ca pela cultura do amendoim dependerá, também, da produtividade alcançada.

Desdobrando épocas dentro de doses de Ca, constata-se que as épocas de semeadura influenciaram o peso de 100 grãos em todas as doses estudadas (Tabela 5). Verifica-se que os menores valores foram obtidos na época 4 , exceção feita à dose $\mathrm{Ca}_{1}$, na qual as épocas 3 e 4 diferiram da época 2. Esses resulta- dos talvez estejam intimamente relacionados com a precipitação pluvial, que diminuiu consideravelmente a partir do início do mês de abril (Fig. 1), afetando o desenvolvimento dos grãos (Tabela 2). De acordo com Rao et al. (1985), na cultura do amendoim, quando a deficiência hídrica ocorre durante a fase de enchimento dos frutos, a relação peso de sementes/ frutos é afetada. Ross \& Kvien (1989) relatam que a deficiência hídrica afeta a composição das sementes, diminuindo o volume e o peso médio das sementes, reduzindo o movimento e absorção de $\mathrm{Ca}$ e outros nutrientes imóveis no floema. Além disso, há, também, redução do fluxo de nutrientes móveis no floema às sementes (Conkerton et al., 1989).

Analisando os resultados obtidos quanto ao rendimento (peso de grãos/peso de vagens) (Tabela 5), desdobrando a interação doses dentro de épocas, verifica-se que ocorreu influência das doses apenas na época 4 , em que a dose $\mathrm{Ca}_{2}$ proporcionou o maior rendimento $(76,5 \%)$, diferindo estatisticamente das doses $\mathrm{Ca}_{1}$ e Ca 4 . Nas demais épocas, as doses de $\mathrm{Ca}$ não afetaram o rendimento, estando, pois, os resultados, de acordo com os obtidos por Tella et al. (1971), Neptune et al. (1982), Quaggio et al. (1982), Fornasieri et al. (1987), Caires (1990, 1994), Smyth \& Cravo (1992) e Fernandez (1996).

\section{CONCLUSÕES}

1. À medida que se atrasa a semeadura há a probabilidade de ocorrer deficiência hídrica no período vegetativo e reprodutivo do amendoim da seca.

2. Há boa produtividade de vagens com cultivo do amendoim da seca, sem irrigação, quando a semeadura é realizada até o início do mês de fevereiro.

3. A resposta do amendoim da seca ao Ca é baixa em solos onde inicialmente se tem alto teor de $\mathrm{Ca} e$ saturação por bases considerada média, principalmente quando a disponibilidade hídrica é um fator limitante.

4. A aplicação de calcário no sulco de semeadura como meio de fornecimento de Ca para a cultura do amendoim é uma prática viável.

\section{REFERÊNCIAS}

ALVA, A.K.; GASCHO, G.J.; GUANG, Y. Soil solution and extractable calcium in gypsum: amended coastal 
plain soil used for peanut culture. Communications in Soil Science and Plant Analysis, New York, v.22, p.99-116, 1991.

AMENDOIM. Agrianual 98: anuário da agricultura brasileira, São Paulo, p.111-117, 1998.

ARAÚJO, N.B. Panorama atual e perspectivas da produção de sementes no Brasil. In: MENTEN, J.O.M. (Ed.). Patógenos em sementes: detecção, dano e controle químico. Piracicaba : ESALQ, 1991.p.4.

BLAMEY, F.P.C.; CHAPMAN, J. Soil amelioration effects on peanut growth, yield and quality. Plant and Soil, Dordrecht, v.65, p.319-334, 1982.

BRASIL. Ministério de Agricultura e Reforma Agrária. Regras para análise de sementes. Brasília : Secretaria Nacional de Defesa Agropecuária, 1992.365p.

BURKHART, L.; COLLINS, E.R. Mineral nutrients in peanuts plant growth. Soil Science Society of America. Proceedings, Madison, v.6, p.272-280, 1941.

CAIRES, E.F. Resposta diferencial de genótipos de amendoim (Arachis hypogaea L.) à calagem. Botucatu : UNESP, 1990. 114p. Dissertação de Mestrado.

CAIRES, E.F. Resposta do amendoim (Arachis hypogaea $\mathrm{L}$.) à calagem e à aplicação de cobalto $\mathrm{e}$ molibdênio. Botucatu : UNESP, 1994. 102p. Tese de Doutorado.

COLWELL, W.E.; BRADY, N.C. The effect of calcium on certain characteristics of peanut fruit. American Society of Agronomy Journal, Madison, v.37, p.696-708, 1945a.

COLWELL, W.E.; BRADY, N.C. The effects of calcium on yield and quality of large-seed type peanuts. American Society of Agronomy Journal, Madison, v.37, n.413-428, 1945b.

CONKERTON, A.J.; ROSS, L.F.; DAIGLE, D.J.; KVIEN, C.S.; McCOMBS, D.S. The effect of drought stress on peanut seed composition. II. Oil, protein and minerals. Oleagineux, Montpellier, v.44, n.12, p.593-602, 1989.

COX, F.R.; REID, P.H. Calcium-boro nutrition as related to canceled damage in peanuts. Agronomy Journal, Madison, v.56, p.173-176, 1964.

COX, F.R.; ADAMS, F.; TUCKER, B.B. Liming, fertilization and mineral nutrition. In: PATTEE, H.E.;
YOUNG, C.T. (Ed.). Peanut Science and

Technology. Yoakum : APRES, 1982. p.139-163.

DEMATTÊ, J.L.I. Levantamento detalhado dos solos do campus experimental de Ilha Solteira. Piracicaba : ESALQ, 1980. 114p.

FERNANDEZ, E.M. Produtividade e qualidade de sementes de amendoim (Arachis hypogaea L.) em função da calagem e do método de secagem. Botucatu : UNESP, 1996. 126p. Tese de Doutorado.

FERNANDEZ, E.M.; ROSOLEM, C.A.; NAKAGAWA, J. Produtividade e qualidade de sementes de amendoim (Arachis hypogaea L.) em função da calagem e do método de secagem. Revista Brasileira de Sementes, Brasília, v.19, n.1, p.34-40, 1997.

FORNASIERI, J.L.; FERREIRA, M.E.; VITTI, G.C.; FORNASIERI FILHO, D. Efeito do uso de calcário e gesso sobre algumas características produtivas do amendoim (Arachis hypogaea L.) "das águas". Científica, São Paulo, v.15, n.1/2, p.45-54, 1987.

HARRIS, H.C.; BROLMANN, J.B. Comparison of calcium and boron deficiencies of peanuts. I. Physiological and yield differences. Agronomy Journal, Madison, v.58, p.575-578, 1966.

KETRING, D.L. Light effect on development of an indeterminate plant. Plant Physiology, Bethesda, v.64, p.665-667, 1979.

KVIEN, C.S.; BRANCH, W.D.; SUMNER, M.E.; CSINOS, A.S. Pod characteristics influencing calcium concentrations in the seed and hull of peanut. Crop Science, Madison. v.28, p.666-671, 1988.

LEONG, S.K.; ONG, C.K. The influence of temperature and soil water deficit on the development and morphology of groundnut. Journal of Experimental Botany, Oxford, v.34, n.148, p.1551-1561, 1983.

MASCARENHAS, J.P.; MACHKIS, L. Chemotropic response of the pollen of Antirrhinum majus to calcium. Plant Physiology, Bethesda, v.39, p.7077, 1964.

NAKAGAWA, J.; ROSOLEM, C.A. Correlação entre algumas características da planta da cultivar "Tatu" de amendoim (Arachis hypogaea L.). Ecossistema, Campinas, v.7, p.5-7, 1982.

NAKAGAWA, J.; NAKAGAWA, J.; IMAIZUMI, I.; ROSSETTO, C.A.V. Efeitos de algumas fontes de fósforo e da calagem na qualidade de sementes de

Pesq. agropec. bras., Brasília, v.35, n.8, p.1549-1558, ago. 2000 
amendoim. Pesquisa Agropecuária Brasileira, Brasília, v.25, n.4, p.505-512, abr. 1990.

NAKAGAWA, J.; NAKAGAWA, J.; IMAIZUMI, I.; ROSSETTO, C.A.V. Efeitos de fontes de fósforo e da calagem na produção de amendoim. Pesquisa Agropecuária Brasileira, Brasília, v.28, n.4, p.421431, abr. 1993.

NAKAGAWA, J.; ROSOLEM, C.A.; ALMEIDA, R.M. Efeito da maturação e dos métodos de secagem na qualidade de sementes de amendoim. Revista Brasileira de Sementes, Brasília, v.8, n.3, p.83-98, 1986.

NEPTUNE, A.M.L.; SICHMANN, W.; MELLO, F.A.F.; LASCA, D.H.C. Efeito da calagem na produção de amendoim cultivado em solos arenosos do Estado de São Paulo. I. Calagem com antecedência ao plantio. Anais da Escola Superior de Agricultura Luiz de Queiroz, Piracicaba, v.39, p.305-317, 1982.

ONO, Y. Flowering and fruiting of peanut plants. Japan Agricultural Research Quarterly, Tsukuba, v.13, n.4, p.226-229, 1979.

PREVISÕES e estimativas das safras agrícolas do Estado de São Paulo: ano agrícola 1991/92. Informações Econômicas, São Paulo, v.22, n.1, p.61-72, 1992.

QUAGGIO, J.A.; DECHEN, A.R.; RAIJ, B. van. Efeitos da aplicação de calcário e gesso sobre a produção de amendoim e lixiviação de bases do solo. Revista Brasileira de Ciência do Solo, Viçosa, v.6, p.189-194, 1982.

RAIJ, B. van; CANTARELLA, H.; QUAGGIO, J.A.; FURLANI, A.M.C. Recomendações de adubação e calagem para o Estado de São Paulo. 2.ed. Campinas : Instituto Agronômico, 1996. 285p. (IAC. Boletim Técnico, 100).

RAO, R.C.N.; SINGH, S.; SIVAKUMAR, M.V.K.; SRIVASTAVA, K.L.; WILLIAMS, J.H. Effect of water deficit at different growth phases of peanut. I. Yield responses. Agronomy Journal, Madison, v.77, p.782-786, 1985.

RAO, R.C.N.; WILLIAMS, J.H.; SIVAKUMAR, M.V.K.; WADIA, K.D.R. Effect of water deficit at different growth phases of peanut. II. Response to drought during preflowering phase. Agronomy Journal, Madison, v.80, p.431-438, 1988.

REED, J.F.; BRADY, N.C. Time and method of supplying calcium as affecting production of peanuts. American Society of Agronomy Journal, Madison, v.40, p.980-996, 1948.

Pesq. agropec. bras., Brasília, v.35, n.8, p.1549-1558, ago. 2000
ROSS, L.F.; KVIEN, C.S. The effect of stress on peanut seed composition. I. Soluble carbohydrates, tartaric acid and phenolics. Oleagineux, Montpellier, v.44, n.6, p.295-301, 1989.

ROSSETTO, C.A.V. Efeitos da colheita e da calagem na produção e qualidade de sementes de amendoim (Arachis hypogaea L.). Botucatu : UNESP, 1993. 114p. Dissertação de Mestrado.

ROSSETTO, C.A.V.; NAKAGAWA, J.; ROSOLEM, C.A. Efeito da época de colheita e da calagem no rendimento de sementes comercializáveis de amendoim cv. Botucatu. Pesquisa Agropecuária Brasileira, Brasília, v.33, n.5, p.665-675, maio 1998.

SAN MARTIN, P. Amendoim: uma planta da história no futuro brasileiro. 2.ed. São Paulo : Icone, 1987. 68p.

SKELTON, B.J.; SHEAR, G.M. Calcium translocation in the peanut (Arachis hypogaea L.). Agronomy Journal, Madison, v.63, p.409-412, 1971.

SMITH, B.W. Arachis hypogaea normal sporogenesis and syngamy with occasional single fertilization. American Journal of Botany, Columbus, v.43, p.81-89, 1956.

SMYTH, T.J.; CRAVO, M.S. Aluminum and calcium constraints to continuous crop production in a Brazilian Amazon oxisol. Agronomy Journal, Madison, v.84, p.843-850, 1992.

TELLA, R.; CANECCHIO FILHO, U.; ROCHA, J.L.V.; FREIRE, E.S.; IGUE, T. Efeito da adubação do amendoim com nitrogênio, fósforo e potássio, na ausência e na presença de calcário. Bragantia, Campinas, v.30, p.39-47, 1971.

WALKER, M.E.; MULLINIX JUNIOR, B.G.; KEISLING, T.C. Calcium level in the peanut fruiting zone as influenced by gypsum partite size and application rate and time. Communications in Soil Science and Plant Analysis, New York, v.12, p.427439, 1981.

WOLT, J.D.; ADAMS, F. Critical levels of soil and nutrient solution calcium for vegetative growth and fruit development of flourunner peanuts. Soil Science Society of America. Journal, Madison, v.43, p.1159-1164, 1979.

YORK JUNIOR, E.T.; COLWELL, W.E. Soil properties, fertilization and maintenance of soil fertility. In: SYMPOSIUM OF THE PEANUT, THE UNPREDICTABLE LEGUME, 1951, Washington. Proceedings. Washington : National Fertilizers Association, 1951. p.122-171. 